\title{
TEKNOLOGI FERMENTASI UNTUK MENINGKATKAN KUALITAS PUPUK ORGANOPLUS
}

\author{
N.M Witariadi ${ }^{1}$ dan Budi Rahayu Tanama Putri ${ }^{2}$
}

\begin{abstract}
ABSTRAK
Kegiatan bertujuan untuk meningkatkan kualitas dari pupuk organoplus dengan menggunakan teknologi fermentasi. Mikroba fermentor (probiotik) berupa bioinokulan berbasis limbah cairan rumen. Metode pelaksanaan meliputi : bahan baku, mikroba lokal, produksi dan kualitas produksi. Bahan baku berupa kotoran ayam, kotoran sapi, mineral kiserit, ampas anggur,dan arang sekam. Pupuk organoplus merupakan hasil fermentasi skala industri karena bahan baku berupa batuan mineral kaya $\mathrm{Mg}$ dan ampas anggur yang dipakai masing-masing sebesar $20 \%$ atau berjumlah $40 \%$ dari total bahan baku. Produk organoplus memiliki keunggulan tersendiri, karena komposisi dan konsentrasi haranya yang jauh berbeda,sehingga produk ini relative tidak memiliki kompetitor yang berarti. Pupuk organoplus berfungsi meningkatkan kadar gula buah dan mencegah serangan jamur pada tanaman hortikultura, sehingga buah yang dihasilkan menjadi lebih berkualitas yaitu lebih manis, daya tahan lebih lama, dan menekan getah kuning (pada buah manggis). Dapat disimpulkan bahwa dengan memanfaatkan teknologi fermentasi, kualitas dari pupuk organoplus dapat ditingkatkan .
\end{abstract}

Kata kunci: teknologi, fermentasi,mikroba ,kualitas pupuk.

\begin{abstract}
The activity aims to improve the quality of organoplus fertilizer by using fermentation technology. Microbial fermentor (probiotic) in the form of bioinoculant based rumen liquid waste. Methods of implementation include: raw materials, local microbes, production and production quality. Raw materials in the form of chicken manure, cow dung, kiserit mineral, wine waste, and charcoal husk. Organoplus fertilizer is the result of industrial-scale fermentation because the raw material is mineral rock rich in $\mathrm{Mg}$ and the wastewater that used each $20 \%$ or $40 \%$ of the total raw material. Organoplus product has its own advantages, because the composition and concentration of hunya far different, so that this product is relative has no significant competitors. Organoplus fertilizer works to increase the sugar content of fruits and prevent fungus attacks on horticultural crops, so the resulting fruit becomes more qualified that is sweeter, longer endurance, and suppress the yellow sap (on the mangosteen fruit). It can be concluded that by utilizing fermentation technology, the quality of organoplus fertilizers can be improved.
\end{abstract}

Keywords: technology, fermentation, microbe, quality of fertilizer.

\section{PENDAHULUAN}

Pertanian organik di Bali, akhir-akhir ini mengalami perkembangan yang sangat besar. Pemanfaatan pupuk organik adalah sarana strategis untuk meningkatkan kesuburan tanah dan produksi pertanian, serta menghindari pencemaran lingkungan. Pemberlakuan pencabutan subsidi

\footnotetext{
${ }^{1}$ Staf Pengajar Fakultas Peternakan Universitas Udayana

${ }^{2}$ Staf Pengajar Fakultas Pertanian Universitas Udayana,witarimade@unud.ac.id
} 
pupuk kimia berpengaruh terhadap aspek sosial ekonomi secara nasional, karena harga pupuk kimia menjadi mahal sehingga pemakaiannya menurun, produktivitas tanah dan tanaman pertanian menjadi rendah. Penerapan teknologi dengan memanfaatkan mikroba lokal (bakteri pengurai) sebagai fermentor, akan dihasilkan pupuk organik yang lebih murah dengan kualitas yang distandarisasi untuk meningkatkan produksi pertanian. Keunggulan dari produk yang dihasilkan terletak pada penerapan teknologi formulasi material organik dengan bahan mineral sumber $\mathrm{Mg}$ dan dekomposer yang dihasilkan dari mikroba dekomposer lokal yang bekerja dengan efektif. Melalui aplikasi teknologi ini dimungkinkan diproduksi pupuk organik yang kaya Mg. Pupuk organik yang dihasilkan dengan kandungan $\mathrm{Mg}$ yang tinggi berfungsi untuk memperbaiki struktur tanah, sebagai sumber karbon, hara makro dan hara mikro, sebagai pemanis buah dan memperbaiki kualitas buah (hasil tanaman). Magnesium merupakan komponen utama penyusun klorofil dan sebagai katalis dalam fotosintesis yang memproduksi karbohidrat yang memberi rasa manis pada buah-buahan.

Pupuk organik berkualitas berarti bahwa pupuk tersebut sesuai standar nasional Indonesia (SNI) serta mengandung hara untuk tanaman yang lebih lengkap dengan dosis yang lebih tinggi. Tehnologi fermentasi menggunakan dekomposer efektif yang mampu menguraikan bahan organik secara lebih sempurna dalam waktu yang lebih singkat. Salah satu hasil dari studi ini adalah pupuk organik yang diformulasikan dengan material dengan kadar mineral magnesium $(\mathrm{Mg})$ dosis tinggi (>20\%) dan mineral kiserit. Mineral kiserit adalah senyawa $\mathrm{Mg}$ dan sulfat yang memiliki kandungan $\mathrm{Mg}$ dalam dosis tinggi. Material tersebut diformulasikan dengan limbah kotoran ayam dan kotoran sapi serta limbah ampas anggur dan serbuk arang sekam. Kotoran ayam mengandung senyawa kalium yang lebih tinggi dari limbah ternak lainnya yaitu mencapai $1,5 \%$. Kandungan $\mathrm{Mg}$ dan kalium yang tinggi pada pupuk organik organoplus telah memacu kandungan gula yang lebih tinggi pada buah-buahan yang dipupuk dengan pupuk organik tersebut. Buah yang dihasilkan dari tanaman yang dipupuk dengan organoplus secara organoleptik lebih renyah, daya simpan lebih lama, dan lebih manis. Indayati Lanya dkk (2009) melaporkan bahwa pemberian 5 ton per hektar mampu meningkatkan kadar gula sebesar 20,14\% pada tanaman melon, kemudian Merit $d k k$ (2011) mendapatkan pada pemberian 6 ton/ha meningkatkan kadar gula rata-rata sebesar 24,34\% pada tanaman anggur, dan Sardiana (2010) mencatat terjadi peningkatan kadar gula buah stroberri ratarata sebesar $26,12 \%$ pada pemberian 8 ton/ha, dan pemberian organoplus pada tanaman manggis telah meningkatkan kadar gula sebesar $16,26 \%$ dan menurunkan serangan penyakit getah kuning pada buah manggis sebesar $30,32 \%$.

Penyediaan pupuk organoplus yang kaya mineral Mg dengan teknologi fermentasi akan mendorong peningkatan kualitas pupuk yang selanjutnya dapat memacu produksi pada buah-buahan. Signifikansi penggunaan pupuk organoplus terhadap kualitas produksi buah-buahan menyebabkan permintaan pupuk ini semakin meningkat.

\section{METODE PELAKSANAAN}

Jenis bahan baku yang dipakai dalam memproduksi organoplus adalah kotoran ayam petelur sebanyak $40 \%$ dan kotoran sapi sebanyak $20 \%$ sebagai sumber Nitrogen $(\mathrm{N})$, limbah anggur dan serbuk arang sekam sebagai sumber Phosphat (P) dan Kalium (K) sebanyak 10-15\%, bahan mineral magnesium karbonat (kadar $\mathrm{Mg}>20 \%$ ) 10-15 \% dan 10-20\% kisrit (CaMgSO4) sebagai sumber $\mathrm{Mg}$. Bahan utama dicampur dan difermentasi menggunakan fermentor dari mikroba lokal yaitu biomin plus . Pemakaian fermentor sebesar $10 \%$ dari total bahan dan setelah tercampur bahan pupuk didiamkan dalam keadaan anaerob selama 10 hari. Selama berlangsung proses fermentasi yang menghasilkan panas, maka suhu pupuk harus tetap dijaga. Pupuk organik atau pupuk organoplus yang dihasilakan sudah distandardisasi memakai Peraturan Menteri Pertanian. Kotoran ayam dan kotoran sapi diperoleh dari kelompok peternak ayam binaan Fakultas Peternakan Universitas Udayana di Desa Babahan Penebel. Kelompok ini menghasilkan rata-rata 5-10 ton kotoran ayam per hari. Material sumber mineral $\mathrm{Mg}$ diperoleh dari penambang limestone yang dilakukan petani 
di daerah Bukit Jimbaran di sekitar kampus Universitas Udayana. Ampas anggur diperoleh dari perusahan anggur di Tabanan mempunyai kadar C-organik 45.3\%, N 2.98\%, P 0.18\% dan K 2.26\%, selain itu akan memberikan unsur $\mathrm{Ca}, \mathrm{Mg}, \mathrm{Mn}, \mathrm{Fe}, \mathrm{Cu}$, dan $\mathrm{Zn}$ (Laboratorium Tanah, 2005), dan serbuk arang sekam diperoleh dari penyosohan gabah di Tabanan.

Produksi pupuk Organoplus (organo-mineral pemanis buah), merupakan usaha pengembangan produksi pupuk organik yang terfortifikasi mineral Mg. Keunggulan dari produk yang dihasilkan dibandingkan dengan usaha sejenis terletak pada penerapan teknologi formulasi material organik dengan bahan mineral sumber $\mathrm{Mg}$ dan dekomposer yang dihasilkan dari mikroba dekomposer lokal yang bekerja dengan efektif. Melalui aplikasi teknologi ini dimungkinkan diproduksi pupuk organik yang kualitas lebih baik (pupuk kaya mineral $\mathrm{Mg}$ ). Pupuk organoplus selain berfungsi seperti pupuk organik pada umumnya yaitu memperbaiki struktur tanah, sebagai sumber karbon, hara makro dan hara mikro, juga berfungsi meningkatkan rasa manis pada buah dan memperbaiki kualitas buah menjadi lebih tahan lama,karena kandungan Mg-nya yang tinggi. Magnesium merupakan komponen utama penyusun klorofil dan sebagai katalis dalam proses fotosintesis yang memproduksi karbohidrat yang memberi rasa manis pada buah-buahan. Proses pembuatan pupuk organoplus dari menyiapkan bahan baku sampai ke pengolahan sebagai berikut:

1) Material Kapur karbonat merupakan kapur yang dihasilkan bukan melalui proses pembakaran tetapi digiling langsung, kapur karbonat ini mengandung kalsium oksida dan magnesium oksida (47\%) serta kalsium karbonat dan magnesium karbonat (85\%), diperoleh dari hasil galian masyarakat lokal yang telah secara tradisional mengetahui karakteristik batuan tersebut di daerah Bukit Jimbaran, Badung

2) Material Kiserit, Kiserit adalah mineral magnesium sulfat yang sangat tidak stabil berkomposisi $\mathrm{MgSO}_{4} \mathrm{H}_{2} \mathrm{O}$, tidak dihasilkan di Indonesia tetapi diimport diperoleh melalui kerjasama dengan penjual zat kimia keperluan analisis laboratorium. Zat ini digunakan untuk fortifikasi batuan mineral $\mathrm{Mg}$ agar memenuhi standar baku yang diperlukan.

3) Fermentor (probiotik) efektif berupa bioinokulan berbasis limbah cairan rumen yang memiliki daya urai efektif (biomin plus), sehingga mampu menguraikan material bahan organik secara lebih cepat dan sempurna.

4) Limbah kotoran ayam ras dan kotoran sapi diperoleh dari kelompok peternak binaan Universitas Udayana di sentra peternakan masyarakat di Desa Babahan Kecamatan Penebel Kabupaten Tabanan

5) Ampas anggur yang diperoleh dari pabrik wine di Kecamatan Kerambitan Kabupaten Tabanan.

6) Serbuk arang sekam diperoleh dari pabrik penyosohan gabah di Tabanan.

7) Komposisi material pupuk adalah: 40\% kotoran ayam, 20\% kotoran sapi, 10\% ampas anggur, $10 \%$ serbuk arang sekam, 10\% kapur karbonat, dan 10\% kiserit. Untuk memproduksi 1 ton pupuk organoplus diperlukan : $400 \mathrm{~kg}$ kotoran ayam, 200kg kotoran sapi, $100 \mathrm{~kg}$ ampas anggur, $100 \mathrm{~kg}$ serbuk arang sekam,100 kg kapur karbonat, $100 \mathrm{~kg}$ kiserit, dan 4 botol dekomposer.

8) Campuran ditimbun dan ditutup rapat dengan terpal dan bagian pinggir terpal diberi beban sehingga jika ada angin terpal tidak terbuka.

9) Diamkan selama 3 hari, kemudian terpal dibuka dan timbunan diaduk untuk tujuan pemberikan airasi pada proses pengomposan. Proses pengomposan yang berhasil akan timbul panas dan dapat dirasakan saat pembongkaran gundukan.

10) Perkirakan setelah 2 minggu pupuk sudah bisa dibongkar dan diangin- anginkan supaya menghilangkan bau amoniak dan sudah dapat dipakai.

11) Pupuk yang sudah difermentasi selanjutnya di ayak sesuai pesanan dan di kemas. Untuk pupuk organoplus berbentuk granular, langkah berikutnya di masukkan ke mesin granular kemudian dikeringkan dan dikemas. 


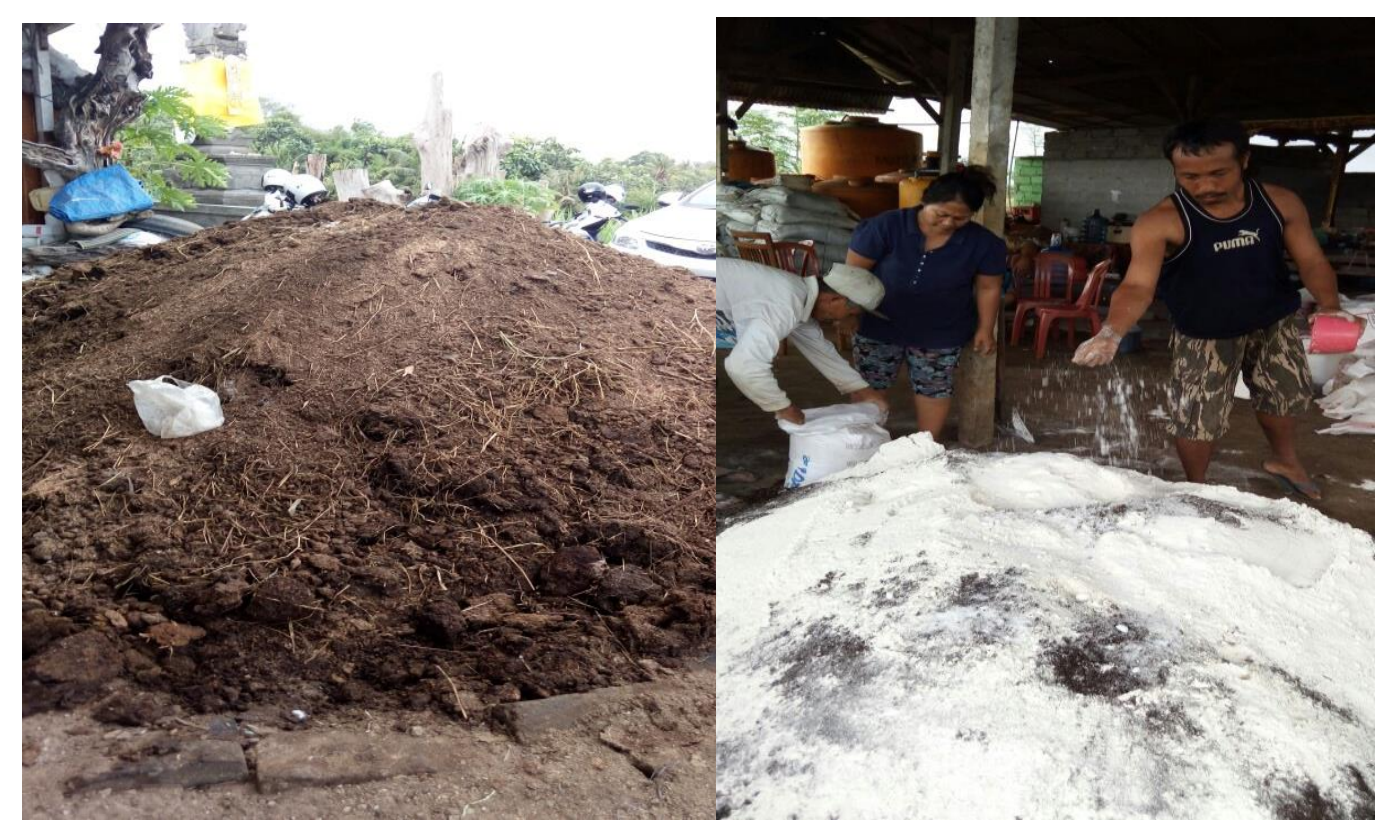

Gambar 1. Bahan baku Pupuk

Gambar 2. Proses Pencampuran Pupuk

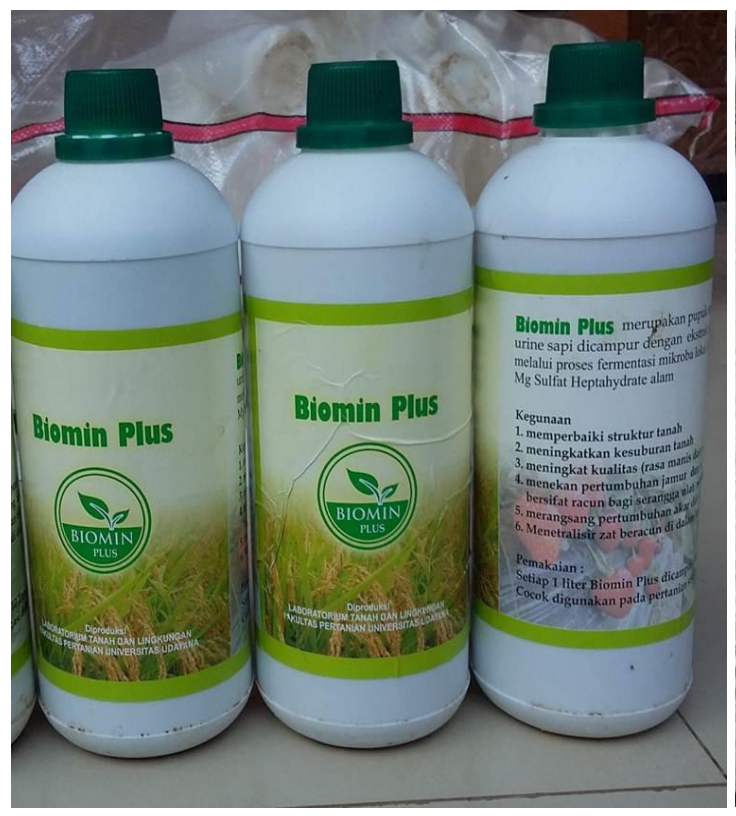

Gambar 3. Fermentor

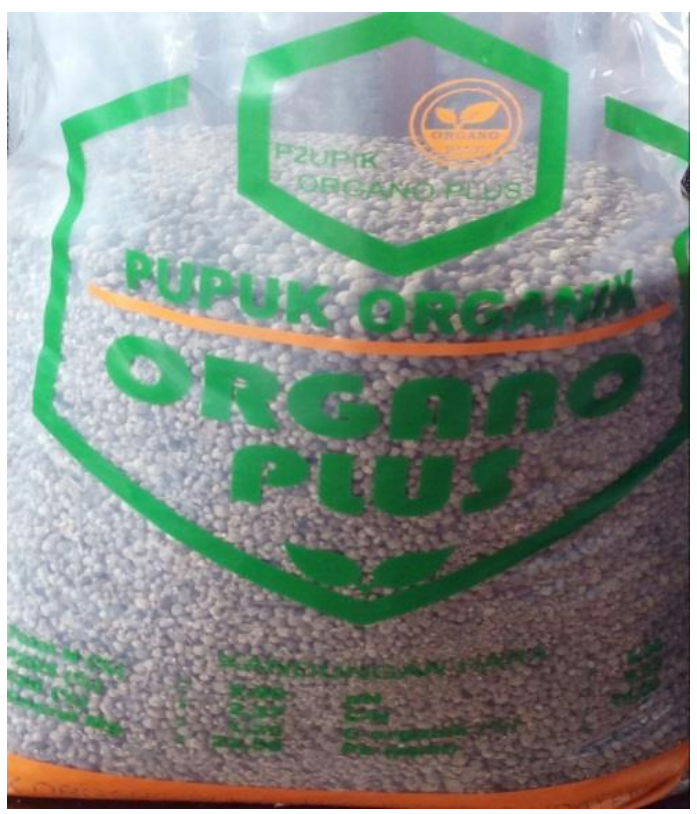

Gambar 4. Pupuk Organoplus

\section{HASIL DAN PEMBAHASAN}

Bahan baku pembuatan pupuk organoplus berasal dari ampas buah anggur atau kotoran ternak yang masih segar dan mempunyai rasio karbohidrat dan nitrogen atau $\mathrm{C} / \mathrm{N}$ yang tinggi antara 50 200, dicampur dengan bahan mineral magnesium karbonat dan magnesium hidroksida. Pengomposan atau fermentasi adalah upaya untuk menurunkan rasio $\mathrm{C} / \mathrm{N}$ bahan menjadi $10-20$, sehingga dapat diserap tanah. Prinsip dari fermentasi anaerob ini adalah bahan limbah organik dihancurkan oleh mikroba dalam kisaran temperatur dan kondisi tertentu. Proses penguraian dipercepat dengan menambah starter dari kultur bakteri sebagai dekomposer. Pengomposan adalah penerapan IPTEK memakai tehnologi fermentasi menggunakan bakteri fibrolitik yang akan 
mengurai bahan sintesis, senyawa kompleks dan pestisida. Starter yang dipakai adalah hasil isolasi dari mikroba lokal disebut biomin plus. Keunggulan pemakaian starter ini adalah proses pengomposan limbah organik menjadi pupuk organik dilakukan dengan cepat, dimana hanya dalam waktu 7-14 hari sudah menjadi pupuk organik. Jenis mikroorganisme yang terdapat pada biomin plus antara lain: 1) Bakteri fotosintetik yang membentuk senyawa-senyawa yang bermanfaat dari sekresi akar tumbuh-tumbuhan, bahan organik dan/atau gas-gas berbahaya seperti hidrogen sulfida, dengan dibantu sinar matahari dan panas sebagai sumber energi. Zat-zat bermanfaat tersebut meliputi asam amino, asam nukleat, zat-zat bioaktif, dan gula, yang semuanya dapat mempercepat pertumbuhan dan perkembangan tanaman; 2) Bakteri asam laktat yang menghasilkan asam laktat dari gula, dan karbohidrat lain yang dihasilkan oleh bakteri fotosintetik dan ragi. Bakteri asam laktat dapat menghancurkan bahan-bahan organik seperti lignin dan selulosa, serta memfermentasikannya tanpa menimbulkan senyawa-senyawa beracun yang ditimbulkan dari pembusukan bahan organik; 3) Ragi dapat menghasilkan senyawa-senyawa yang bermanfaat bagi pertumbuhan tanaman dari asam amino dan gula di dalam tanah yang dikeluarkan oleh bakteri fotosintetik atau bahan organik melalui proses fermentasi; 4) Actinomycetes menghasilkan zat-zat anti mikroba dari asam amino yang dikeluarkan oleh bakteri fotosintetik dan bahan organik. Zat-zat yang dihasilkan oleh mikroorganisme ini dapat menekan pertumbuhan jamur dan bakteri yang merugikan tanaman, tetapi dapat hidup berdampingan dengan bakteri fotosintetik. Setiap jenis mikroorganisme mempunyai fungsi masing-masing dalam proses fermentasi bahan organik.

Produk utama yang dihasilkan adalah Pupuk Organoplus (pupuk organo-mineral kaya Mg sebagai pemanis buah). Pupuk Organoplus adalah pupuk organik kaya mineral Mg yang berfungsi meningkatkan kadar gula buah dan mencegah serangan jamur pada tanaman hortikultura, sehingga buah yang dihasilkan menjadi lebih berkualitas yaitu lebih manis, daya tahan lebih lama, dan menekan getah kuning (pada buah manggis). Pegembangan pupuk Organoplus (organo-mineral pemanis buah), merupakan pupuk organik yang terfortifikasi mineral $\mathrm{Mg}$, dimana keunggulan dari produk yang dihasilkan terletak pada penerapan teknologi formulasi material organik dengan bahan mineral sumber $\mathrm{Mg}$ dan dekomposer yang dihasilkan dari mikroba dekomposer lokal yang bekerja dengan efektif. Magnesium merupakan komponen utama penyusun klorofil dan sebagai katalis dalam fotosintesis yang memproduksi karbohidrat yang memberi rasa manis pada buah-buahan. Kualitas atau Standar Produk pupuk Organoplus akan disesuaikan agar memenuhi standar nasional (SNI). Pupuk Organoplus merupakan hasil fermentasi mikroba lokal dalam skala industri akan distandarisasi sesuai dengan Peraturan Menteri Pertanian: No. 28/Permentan/2009 menyebutkan bahwa syarat dan kualitas pupuk organik di Indonesia adalah: $\mathrm{C} / \mathrm{N}=12-20 \%$, pH: 4-8, kadar air: 15\%, C-organik minimal 12\%. : $2.79 \% \mathrm{~N}, 0.52 \% \mathrm{P}_{2} \mathrm{O}_{5}, 2.29 \% \mathrm{~K}_{2} \mathrm{O}$ dan $\mathrm{Mg} 4,26 \%$ dengan konsentrasi yang lebih tinggi dari pupuk organik lainnya, serta mengandung unsur mikro seperti seng $(\mathrm{Zn})$, tembaga $(\mathrm{Cu})$, besi $(\mathrm{Fe})$, molybdenum (Mo). Pupuk organoplus ( Pupuk Organik kaya $\mathrm{Mg}$ ) berdasarkan hasil uji laboratorium terhadap komposisi unsur hara mengandung : $\mathrm{C} / \mathrm{N}=$ 12\%, pH: 6,90, C-organik 14\% : 2,90\% N, 2,37\% $\mathrm{P}_{2} \mathrm{O}_{5}, 1,39 \% \mathrm{~K}_{2} \mathrm{O}$ dan $\mathrm{Mg} 22,58 \%$. Hasil uji laboratorium terhadap pupuk Organoplus bahwa kandungan hara yang diperoleh sudah sesuai dengan standarisasi pupuk organik, sehingga pupuk Organoplus bisa dipasarkan sehingga aplikasi pada tanaman dapat dilihat dari produksi yang dihasilkan.

\section{KESIMPULAN DAN SARAN}

Berdasarkan hasil kegiatan diatas, dapat disimpulkan bahwa melalui teknologi fermentasi menggunakan mikroba lokal (biomin plus) dihasilkan pupuk organik kaya $\mathrm{Mg}$ untuk meningkatkan rasa manis pada buah-buahan dan kualitas pupuk sesuai dengan Standar Nasional Indonesia (SNI) 
Saran yang diajukan bahwa produksi pupuk organoplus harus dijaga kualitasnya melalui penerapan teknologi fermentasi yang tepat dan melakukan uji laborartorium untuk menjaga kandungan hara tetap terjaga.

Tabel 1. Komposisi Campuran Pupuk Organoplus

\begin{tabular}{|l|l|l|}
\hline No & \multicolumn{1}{|c|}{ Bahan } & Jumlah \\
\hline 1 & Kotoran Ayam & $40 \%$ \\
\hline 2 & Kotoran Sapi & $20 \%$ \\
\hline 3 & Limbah Anggur & $10 \%$ \\
\hline 4 & Serbuk sekam arang & $10 \%$ \\
\hline 5 & Mineral Magnesium karbonat & $10 \%$ \\
\hline 6 & Kisrit $\left(\mathrm{CaMgSO}_{4}\right)$ & $10 \%$ \\
\hline 7 & Biomin plus (fermentor) diluar komposisi & $10 \%$ \\
\hline
\end{tabular}

\section{UCAPAN TERIMA KASIH}

Penulis mengucapkan terimakasih kepada Rektor Universitas Udayana, melalui ketua LPPM Universitas Udayana yang telah memberikan dana, sehingga kegiatan pengabdian (IbIKK) terlaksana sesuai dengan rencana.

\section{DAFTAR PUSTAKA}

Mosher, A. T. 1987. Menggerakkan dan Membangun Pertanian. CV Yasaguna, Jakarta Mubyarto, 1989.Pengantar Ekonomi Pertanian. LP3ES, Jakarta.

Suparta, I.N., Budiartha,I.W., Suciani, Putri,B.R.T., Agribisnis Peternakan Meraih Kesempatan Menuju Sukses. Pustaka Nayottama, Denpasar.

Suryana. 2008. Kewirausahaan. Pedoman Praktis: Kiat dan Proses Menuju Sukses. Edisi Ketiga. Salemba Empat, Jakarta. 